\title{
Submicrometric magnetic nanoporous carbons derived from metal-organic frameworks enabling automated electromagnet-assisted on-line solid-phase extraction
}

\author{
Rejane M. Frizzarin, Carlos Palomino Cabello, Maria del Mar Bauzà, Lindomar A. Portugal, \\ Fernando Maya*, Víctor Cerdà, José M. Estela, Gemma Turnes Palomino*
}

\author{
Department of Chemistry, University of the Balearic Islands, Carretera de Valldemosa km 7.5, \\ 07122, Palma de Mallorca, Spain. \\ *Corresponding author. Tel.: +34 971173 260; Fax: +34 971173426. \\ E-mail address: fernando.maya@uib.es; g.turnes@uib.es
}

Table of contents

Page S-2. Experimental domain, matrix with coded values and analytical responses for two level full factorial design for the determination of anionic surfactants by $\mu$ MNPC.

Page S-3. ANOVA for the two full factorial design of Table 2.

Page S-4. Doehlert Matrix with domain, levels, assays and analytical responses for the optimization of anionic surfactant determination.

Page S-5. BET surface area plot of the prepared $\mu$ MNPCs.

Page S-6. Pareto Chart obtained by factorial design for determination of anionic surfactants. 
Table S1. Experimental domain, matrix with coded values and analytical responses for two level full factorial design for the determination of anionic surfactants by $\mu$ MNPC.

\begin{tabular}{|c|c|c|c|}
\hline \multirow{2}{*}{ Independent variable } & \multicolumn{3}{|c|}{ Levels } \\
\hline & $(-)$ & (0) & $(+)$ \\
\hline Methylene blue $\left(\mathrm{mg} \mathrm{L}^{-1}\right)$ & 1.0 & 5.5 & 10.0 \\
\hline Methanol $(\%, v / v)$ & 10 & 50 & 90 \\
\hline \multicolumn{4}{|c|}{ Factorial design matrix } \\
\hline \multicolumn{2}{|c|}{ Methylene blue } & Methanol & Absorbance* \\
\hline 1 & - & - & 0.113 \\
\hline 2 & + & - & 0.229 \\
\hline 3 & - & + & 0.701 \\
\hline 4 & + & + & 0.906 \\
\hline 5 & 0 & 0 & 0.414 \\
\hline 6 & 0 & 0 & 0.337 \\
\hline 7 & 0 & 0 & 0.404 \\
\hline 8 & 0 & 0 & 0.404 \\
\hline
\end{tabular}

(-) lowest level; (+) highest level; (0) central point.

* blank subtracted. 
Table S2. ANOVA for the two full factorial design of Table 2.

\begin{tabular}{cccccc}
\hline & SS & $\boldsymbol{d} \boldsymbol{f}$ & $\boldsymbol{M S}$ & $\boldsymbol{F}$ & $\boldsymbol{p}$ \\
\hline (1) MB & 0.02576 & 1 & 0.0258 & 20.4622 & 0.0202 \\
$(1) \mathrm{MeOH}$ & 0.4001 & 1 & 0.4001 & 317.7782 & 0.0004 \\
Lack of fit & 0.0020 & 1 & 0.0020 & 1.5730 & 0.2986 \\
Pure error & 0.01901 & 1 & 0.0190 & 15.1023 & 0.0302 \\
Total SS & 0.0038 & 3 & 0.0013 & & \\
\hline
\end{tabular}

$R=0.9494 ;$ Adj.: 0.9115; Pure error $=0.0013 ; p=0.05$. 
Table S3. Doehlert Matrix with domain, levels, assays and analytical responses for the optimization of anionic surfactant determination.

\begin{tabular}{|c|c|c|c|c|c|c|c|}
\hline \multirow{2}{*}{ Independent variable } & \multicolumn{7}{|c|}{ Coded and real values (levels) } \\
\hline & -1 & -0.866 & -0.5 & 0 & +0.5 & +0.866 & +1 \\
\hline Methylene blue $\left(\mathrm{mg} \mathrm{L}^{-1}\right)$ & 5.0 & - & 10.0 & 15.0 & 20.0 & - & 25.0 \\
\hline Methanol $(\%, v / v)$ & - & 50 & - & 75 & - & 100 & - \\
\hline \multicolumn{8}{|c|}{ Matrix Doehlert } \\
\hline Assay & \multicolumn{2}{|c|}{ Methylene blue } & \multicolumn{3}{|c|}{ Methanol } & \multicolumn{2}{|c|}{ Absorbance* $^{*}$} \\
\hline 1 & \multicolumn{2}{|c|}{-0.5} & \multicolumn{3}{|c|}{+0.866} & \multicolumn{2}{|c|}{1.228} \\
\hline 2 & \multicolumn{2}{|c|}{+0.5} & \multicolumn{3}{|c|}{+0.866} & \multicolumn{2}{|c|}{1.228} \\
\hline 3 & \multicolumn{2}{|r|}{-1} & \multicolumn{3}{|c|}{0} & \multicolumn{2}{|c|}{0.743} \\
\hline 4 & \multicolumn{2}{|r|}{0} & \multicolumn{3}{|c|}{0} & \multicolumn{2}{|c|}{1.002} \\
\hline 5 & \multicolumn{2}{|r|}{+1} & \multicolumn{3}{|c|}{0} & \multicolumn{2}{|c|}{0.792} \\
\hline 6 & \multicolumn{2}{|c|}{-0.5} & \multicolumn{3}{|c|}{-0.866} & \multicolumn{2}{|c|}{0.090} \\
\hline 7 & \multicolumn{2}{|c|}{+0.5} & \multicolumn{3}{|c|}{-0.866} & \multicolumn{2}{|c|}{0.166} \\
\hline 8 & \multicolumn{2}{|r|}{0} & \multicolumn{3}{|c|}{0} & \multicolumn{2}{|c|}{0.743} \\
\hline 9 & \multicolumn{2}{|r|}{0} & \multicolumn{3}{|c|}{0} & \multicolumn{2}{|c|}{0.609} \\
\hline 10 & \multicolumn{2}{|r|}{0} & \multicolumn{3}{|c|}{0} & \multicolumn{2}{|c|}{0.981} \\
\hline
\end{tabular}

* Blank subtracted 


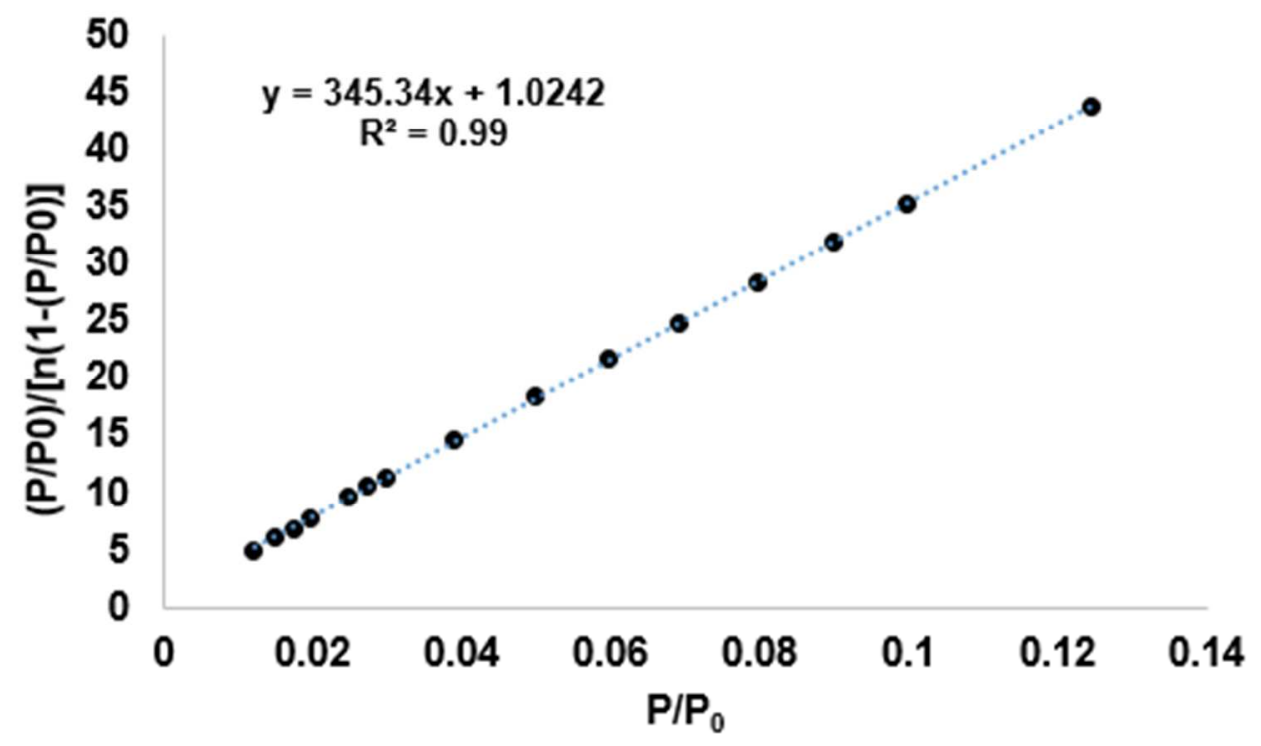

Figure S1. BET surface area plot of the prepared $\mu$ MNPCs. 


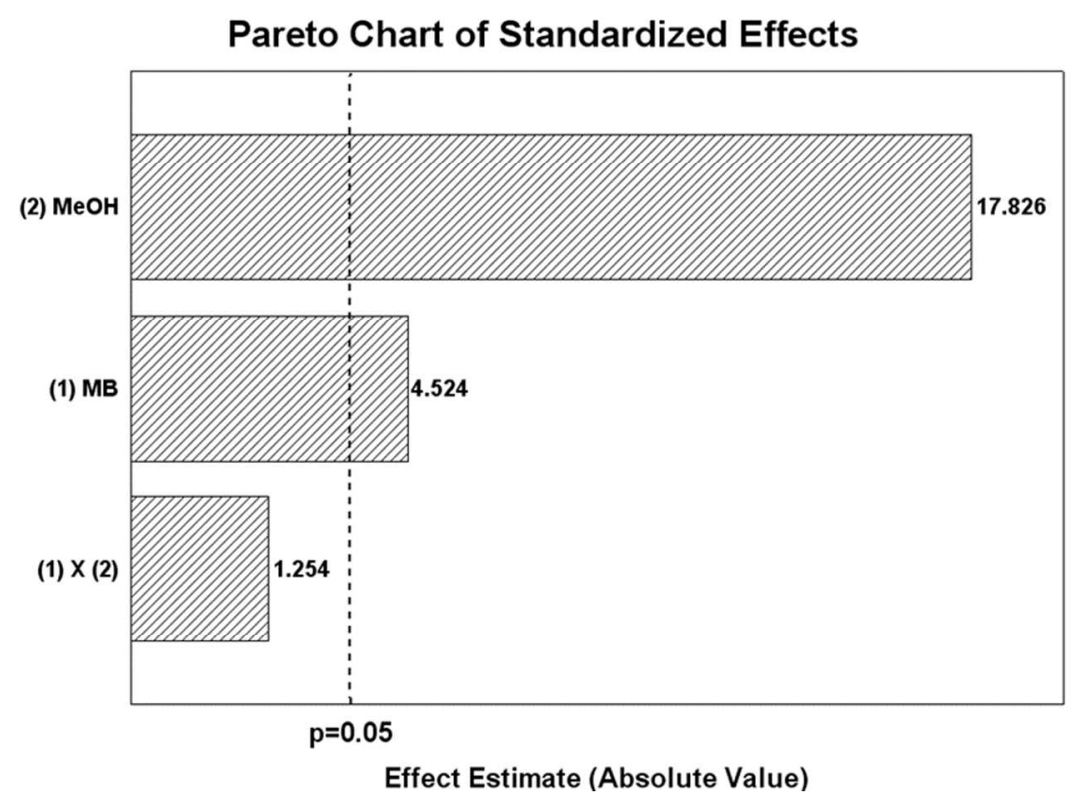

Figure S2. Pareto Chart obtained by factorial design for determination of anionic surfactants (MeOH: methanol; MB: methylene blue; (1) x (2): interaction between the two factors (methanol and methylene blue); p: confidence level (95\%)). 